\title{
THE EFFECT OF CALCIUM SUPPLEMENTATION ON THE ECONOMICALLY IMPORTANT HEALTH PARAMETERS IN A LARGE DAIRY HERD
}

\author{
Fodor István ${ }^{1^{*}}$, Sulyok Dóra ${ }^{1}$, Ivanyos Dorottya ${ }^{1}$, Bartyik János ${ }^{2}$ and Ózsvári László ${ }^{1}$ \\ ${ }^{1}$ Department of Veterinary Forensics and Economics, University of Veterinary Medicine, Budapest, Hungary \\ ${ }^{2}$ Enying Agricultural Ltd., Mátyásdomb-Ágostonpuszta, Hungary \\ https://doi.org/10.47833/2020.1.AGR.009
}

\section{Keywords: \\ Dairy cattle \\ Reproduction \\ Animal health \\ Calcium \\ Mastitis}

\section{Article history:}

Received 2 Nov 2019

Revised 20 Nov 2019

Accepted 25 Nov 2019

\begin{abstract}
The aim of our study was to investigate the association of per os calcium supplementation with the occurrence of animal health disorders in a large Hungarian dairy herd. The treatment of cows consisted of two per os calcium boluses on the day after calving. The probability of insemination, culling, mastitis, uterine disorders, and lameness were compared in the treated $(n=168)$ vs. control cows ( $n=136)$ within 60 days in milk. Data were analysed by logistic regression. Cows that received calcium boluses were 8.09-times more likely to be inseminated $(P<0.0001)$ and 0.34-times less likely to be culled $(P=0.001)$ within 60 days in milk. Treated cows had reduced odds of developing mastitis (odds ratio, $O R=0.50, P=0.0387$ ) and lameness $(O R=0.15, P=0.005)$ compared to their control herdmates. Per os calcium boluses can improve animal health in early lactation in high producing dairy cattle.
\end{abstract}

\section{Introduction}

Calcium is an essential mineral for the body, since it is needed for the normal muscle contraction, blood coagulation, nerve transmission, furthermore, it constitutes part of the skeletal system. Calcium also regulates the activity of several hormones [1]. Dairy cows, especially the multiparous, high-producing animals, meet an extremely high demand for calcium to produce milk [4]. The calcium loss must be replaced by increasing bone resorption and calcium absorption from the intestines.

The normal blood calcium concentration ranges between 2.1 and $2.5 \mathrm{mmol} / \mathrm{l}$ in adult cows [11]. Hypocalcemia occurs when blood calcium concentration decreases below $2.1 \mathrm{mmol} / \mathrm{l}$. Hypocalcemia appears in either clinical or subclinical form. The prevalence of clinical hypocalcemia is about $5 \%$, whereas that of the subclinical form may exceed $50 \%$ in large-scale, high-producing dairy herds. Both forms influence the health and the production of the cows at the onset of lactation [11]. Clinical hypocalcemia has various symptoms from excitement and teeth grinding to lateral recumbency and coma. The subclinical form has no clinical symptoms, but decreases the reproductive performance, and increases the risk of other diseases (e.g. retained placenta, delayed uterine involution) [5],[10]. Subclinical hypocalcemia is more important from an economic point of view than the clinical form [8] Based on the previously published figures for prevalence and loss per case, Oetzel (2013) estimated that clinical and subclinical hypocalcemia cause 12,000 and 48,750 USD loss per year, respectively. In order to avoid the effects of hypocalcemia on production and health, calcium supplementation preferably per os - is performed, because it raises blood calcium concentration consistently for a longer period of time [1],[3].

\footnotetext{
* Corresponding author. Tel.: +36 1478 4185; fax: +3614784186

E-mail address: fodor.istvan@univet.hu
} 
The aim of our study was to investigate the association of per os calcium supplementation with the occurrence of animal health disorders in the first 60 days of lactation in a large dairy herd in Hungary.

\section{Method}

Our study was carried out in a dairy herd with more than 2,000 cows in Western Hungary. The average 305-day milk yield and calving interval were $10,699 \mathrm{~kg}$ and 409 days, respectively, in this herd in 2018. The herd management decided to introduce a calcium supplement for the cows in the calving pen from May 2019 in order to improve production and animal health in early lactation. Each cow received two per os boluses of calcium (Calcitop ${ }^{T M}$, Resco, Tienen, Belgium) - containing calcium phosphate and calcium formate - at the same time on the next day after calving. The parameters of cows that calved between 12 May 2019 and 19 June 2019 (treated group) were compared to those that calved in the same period in the previous year (i.e. between 12 May 2018 and 19 June 2018; control group). This period was chosen as control in order to account for the possible effects of heat stress. No major management changes were implemented between the two periods that could significantly affect the outcome of the study.

Information about cow ID, calving date, number of calving, date and number of inseminations, culling date (including sales for slaughter and death), and date of treatments were collected retrospectively. The following parameters were analysed in our study: insemination within 60 days in milk (INS), culling within 60 days in milk (CUL), clinical mastitis within 60 days in milk (MAST), uterine disorders within 60 days in milk (MET), and lameness within 60 days in milk (LAM). Each parameter was analysed as a binary (yes/no) variable. In the statistical analysis, logistic regression models were applied, with treatment and lactation number as explanatory variables, and one of the parameters as the dependent variable. The statistical analysis was performed in $\mathrm{R}$ version 3. 5. 1 . [9].

\section{Results}

Altogether, the results of 304 cows were analysed in our study. The number of cows in the treated and the control groups were 168 and 136, respectively. The descriptive statistics for each group are provided in Table 1.

Table 1. The descriptive statistics of the studied parameters by treatment group

\begin{tabular}{|l|c|c|c|c|c|c|c|}
\hline \multicolumn{1}{|c|}{ Group } & $\begin{array}{c}\text { Primiparous } \\
\text { cows }(n)\end{array}$ & $\begin{array}{c}\text { Multiparous } \\
\text { cows }(n)\end{array}$ & INS (\%) & CUL (\%) & $\begin{array}{c}\text { MAST } \\
(\%)\end{array}$ & MET (\%) & LAM (\%) \\
\hline $\begin{array}{l}\text { Control } \\
(\mathrm{n}=136)\end{array}$ & 64 & 72 & 10.29 & 23.53 & 18.38 & 83.82 & 7.35 \\
\hline $\begin{array}{l}\text { Calcium } \\
\text { supplement } \\
(\mathrm{n}=168)\end{array}$ & 72 & 96 & 48.21 & 9.52 & 10.71 & 88.10 & 1.19 \\
\hline
\end{tabular}

INS: insemination within 60 days in milk; CUL: culling within 60 days in milk; MAST: clinical mastitis within 60 days in milk; MET: uterine disorders within 60 days in milk; LAM: lameness within 60 days in milk (LAM)

Only $10.29 \%$ of the control cows were inseminated within 60 days after calving, whereas nearly half of the treated cows received at least one insemination in the same period. More than one-fifth of the control cows were culled within 60 days in milk compared to $9.52 \%$ in the treated group. More than $80 \%$ (!) of the cows suffered from uterine disorders (e.g. clinical metritis, purulent vaginal discharge, prolonged uterine involution), however, the incidence of lameness was low in both groups. The results of the statistical analyses are summarized in Table 2. 
Table 2. The studied parameters of the cows by treatment and parity $(n=304)$

\begin{tabular}{|l|l|c|c|c|}
\hline \multicolumn{1}{|c|}{ Parameter } & \multicolumn{1}{|c|}{ Group } & Odds ratio & 95\% confidence interval & $P$ \\
\hline \multirow{2}{*}{ INS } & Calcium supplement $^{1}$ & 8.09 & $4.42-15.74$ & $<0.0001$ \\
\cline { 2 - 5 } & Multiparous $^{2}$ & 1.10 & $0.65-1.89$ & 0.7219 \\
\hline \multirow{2}{*}{ CUL } & Calcium supplement $^{*}$ MAST & 0.34 & $0.18-0.66$ & 0.0010 \\
\cline { 2 - 5 } & Multiparous & 0.59 & $0.31-1.11$ & 0.1023 \\
\hline \multirow{2}{*}{ MET } & Calcium supplement & 0.50 & $0.25-0.96$ & 0.0387 \\
\cline { 2 - 5 } & Multiparous & 3.22 & $1.57-7.18$ & 0.0012 \\
\hline \multirow{2}{*}{ LAM } & Calcium supplement & 1.44 & $0.75-2.79$ & 0.2726 \\
\cline { 2 - 5 } & Multiparous & 0.80 & $0.41-1.55$ & 0.5177 \\
\cline { 2 - 5 } & Calcium supplement & 0.15 & $0.02-0.59$ & 0.0050 \\
\cline { 2 - 5 } & Multiparous & 0.86 & $0.26-2.84$ & 0.7940 \\
\hline
\end{tabular}

${ }^{1}$ using the control group as the reference

2 using primiparous cows as the reference

INS: insemination within 60 days in milk; CUL: culling within 60 days in milk; MAST: clinical mastitis within 60 days in milk; MET: uterine disorders within 60 days in milk; LAM: lameness within 60 days in milk (LAM)

The per os calcium supplementation was associated with a 8.09-fold increase in the odds of being inseminated within 60 days in milk compared to the untreated control cows $(P<0.0001)$. At the same time, the use of calcium boluses was associated with a significant decrease in the odds of culling $(P=0.0010)$. Those cows that received calcium supplementation were less likely to develop mastitis $(P=0.0387)$ and to become lame $(P=0.0050)$. Parity did not play a significant role in the analysed parameters, except for multiparous cows having 3.22-times higher odds of having mastitis compared to primiparous cows $(P=0.0012)$.

\section{Discussion}

Prevention of hypocalcemia is important in reducing the risk of diseases during transition period, and in decreasing the negative effects of calcium imbalance on reproductive performance [6],[11]. The use of per os boluses is an increasingly applied way of calcium supplementation in dairy cows, which is especially important after calving, because of the expected nadir in blood calcium concentrations [2],[7]. We found that the use of calcium boluses was associated with an increased probability of insemination within 60 days in milk. This finding is supported by the results of Rodríguez et al. (2017), who found that the first estrus occurred sooner after calving in normocalcemic cows compared to their hypocalcemic herdmates. On the contrary, in a study of 1,426 cows in Germany, calcium status was not associated with days to first insemination [11]. In this study we did not categorize cows according to their blood calcium levels, but according to their calcium supplementation status, which could cause differences compared to other studies.

In our study those cows that received calcium boluses were less likely to be culled. Venjakob et al. (2018) found that hypocalcemic cows were 1.69-times more likely to be culled within 60 days in milk compared to the normocalcemic ones.

According to our results, control cows were twice as likely to suffer from clinical mastitis, and therefore, to receive udder treatment compared to the supplemented cows. In a large-scale study [6], calcium status was not associated with the occurrence of clinical mastitis, however, in that study it was concluded that a single postpartum blood sample may not be enough to classify cows according to their blood calcium status.

We found no significant association between calcium supplementation and the occurrence of uterine disorders within 60 days in milk, which supports the finding of Neves et al. (2018). On the contrary, in the study of Rodríguez et al. (2017), metritis was 4.3-times more likely in cows with 
hypocalcemia compared to the normocalcemic cows. In the present study, however, we did not investigate the occurrence of metritis, exclusively, since we took a wider range of uterine disorders into account (e.g. purulent vaginal discharge), which could cause differences compared to other studies.

Calcium supplemented cows were significantly less likely to become lame in our study. Generally, lame cows are considered as a group that could benefit greatly from calcium supplementation, e.g. in a study of 927 dairy cattle, lame cows experienced 0.34 less health events within 30 days in milk, compared to their not treated counterparts [7].

\section{Conclusions}

The effects of postpartum hypocalcemia can be counterbalanced with oral calcium supplementation of the cows after calving. Per os calcium boluses can improve reproductive performance, reduce culling risk, and decrease the risk of mastitis and lameness in early lactation.

\section{Acknowledgment}

The Project was supported by the European Union and co-financed by the European Social Fund: (1) EFOP-3.6.1-16-2016-00024 'Innovations for Intelligent Specialisation on the University of Veterinary Science and the Faculty of Agricultural and Food Sciences of the Széchenyi István University Cooperation'; (2) EFOP-3.6.2-16-2017-00012 'Development of a product chain model for functional, healthy and safe foods from farm to fork based on a thematic research network'; and (3) EFOP-3.6.3-VEKOP-16-2017-00005 'Strengthening the scientific replacement by supporting the academic workshops and programs of students, developing a mentoring process'.

\section{References}

[1] C. D. Blanc, M. Van der List, S. S. Aly, H. A. Rossow, and N. Silva-del-Río, "Blood calcium dynamics after prophylactic treatment of subclinical hypocalcemia with oral or intravenous calcium", J. Dairy Sci., vol. 97, no. 11, pp. 6901-6906, 2014.

[2] E. Brydl, L. Könyves, V. Jurkovich, P. Rafai, L. Tegzes, "Occurrence of subclinical metabolic disorders in large-scale dairy herds in Hungary in 2001", Proc. ISAH 2003, Mexico, pp. 23-27, 2003.

[3] J. P. Goff, and R. L. Horst, "Oral administration of calcium salts for treatment of hypocalcemia in cattle", J. Dairy Sci., vol. 76, no. 1, pp. 101-108, 1993.

[4] R. L. Horst, J. P. Goff, and T. A. Reinhardt, "Calcium and vitamin D metabolism in the dairy cow", J. Dairy Sci., vol. 77, no. 7, 1936-1951, 1994.

[5] G. Kürtös, "The effect of hypocalcaemia and calcium supplementation on the uterine contractility in postpartum cows", Thesis, SZIU-FVS, Budapest, p. 46, 2015.

[6] R. N. Neves, B. M. Leno, M. D. Curler, M. J. Thomas, T.R. Overton, and J. A. A. McArt, "Association of immediate postpartum plasma calcium concentration with early-lactation clinical diseases, culling, reproduction, and milk production in Holstein cows", J. Dairy Sci., vol. 101, no. 1, pp. 547-555, 2018.

[7] G. R. Oetzel, and B.E. Miller, "Effect of oral calcium bolus supplementation on early-lactation health and milk yield in commercial dairy herds", J. Dairy Sci., vol. 95, no. 12, pp. 7051-7065, 2012.

[8] G. R. Oetzel. "Oral Calcium Supplementation in Peripartum Dairy Cows", Vet. Clin. N. Am. - Food A., vol. 29, no. 2, pp. 447-455, 2013.

[9] R Core Team: R: A language and environment for statistical computing. R Foundation for Statistical Computing, Vienna, Austria. 2018. http://www.R-project.org/

[10] E. M. Rodríguez, A. Arís, and A. Bach, "Associations between subclinical hypocalcemia and postparturient diseases in dairy cows", J. Dairy Sci., vol. 100, no. 9, pp. 7427-7434, 2017.

[11] P. L. Venjakob, L. Pieper, W. Heuwieser, and S. Borchardt, "Association of postpartum hypocalcemia with earlylactation milk yield, reproductive performance, and culling in dairy cows", J. Dairy Sci., vol. 101, no. 10, pp. 93969405, 2018. 